\title{
Impact of respiratory muscle training on blood gases and pulmonary function among patients with cervical spinal cord injury
}

\begin{abstract}
Background: Pulmonary difficulties is the most common cause of morbidity and mortality following spinal cord injury, which is the main cause of chronic respiratory failure in young adults.

Objective: This study aimed to investigate the effect of resistive respiratory muscle training on blood gases and pulmonary function of patients with cervical spinal cord injury.

Methods: Thirty six patients with complete spinal cord injury at level from C5 to $\mathrm{C} 8$ of both sexes (23 males and 9 females), their age ranged from 23-41 years ( $30.51 \pm 6.82$ year) were selected from ICU of Cairo University Hospital participated in this study. Their height ranged between $149-185 \mathrm{~cm}$. Participants equally enrolled to either training group (group A) or control group (group B). The respiratory muscle resisted training program was started for group (A) after the clinical stability of patient condition with a threshold positive expiratory pressure device using a three-way valve system via flanged mouthpiece. The patient performed six work sets, five minutes in duration, with a rest period in between for three minutes. All patients received a 45 minutes training/day, five days/ week for six weeks. The arterial blood gases and pulmonary function test are measured before and after exercise program.
\end{abstract}

Results: the mean value of heart rate (HR), respiratory rate (RR), partial pressure of arterial carbon dioxide $\left(\mathrm{PaCO}_{2}\right)$ and $\mathrm{PH}$ revealed significant reduction, where forced vital capacity (FVC), forced expiratory volume in the first second $\left(\mathrm{FEV}_{1}\right)$ and partial pressure of arterial oxygen $\left(\mathrm{PaO}_{2}\right)$ revealed significant increase in group (A) at the end of the study. However, changes in group (B) were not significant. Moreover, there were significant differences between both groups at the end of the study $(\mathrm{P}<0.05)$.

Conclusion: Resistive respiratory muscle training improves blood gases and pulmonary function suggesting this intervention as an efficacious therapy for patients with cervical spinal cord injury.

Keywords: arterial blood gases, breathing exercises, spinal cord injury, pulmonary function
Volume 3 Issue 5 - 2018

\author{
Shehab M Abd El- Kader \\ Department of Physical Therapy for Cardiopulmonary \\ Disorders and Geriatrics, Cairo University, Egypt
}

Correspondence: Shehab M Abd El- Kader, Department of Physical Therapy for Cardiopulmonary Disorders and Geriatrics, Faculty of Physical Therapy, Cairo University, Egypt. Email profshihab@live.com

Received: January 26, 2018| Published: October 12, 2018

\section{Introduction}

Spinal cord injury (SCI) characterized with respiratory difficulties, which is the most common cause of morbidity, and mortality as the prognosis for the patient sustaining spinal cord injury has until this century remained poor. ${ }^{1}$ Individuals with spinal cord injury have high risk of pulmonary complications because of neurological deficits. ${ }^{2}$ Individuals with cervical SCI had reduced vital capacity (VC) and total lung capacity (TLC) below the lower limit of normal. ${ }^{3}$

Spinal cord injury resulted in reduction in lung volumes as result of respiratory muscles dysfunction. However, reduction in compliance of lung and chest, increased compliance of the abdominal wall and stiffness of rib cage in addition to paradoxical movements of chest wall contribute to breathing difficulties. ${ }^{4}$ While, expiratory muscle altered function reduced cough effectiveness and mucus retention. ${ }^{5}$ However, cervical SCI demonstrated increased vagal activity, secretions production, bronchospasms and pulmonary edema, therefore these pulmonary complications is the main cause of morbidity and mortality among individuals with SCI. ${ }^{6}$
The total management of patients requires a holistic, multidisciplinary approach to ensure effective rehabilitation, which depends upon awareness of the risks, and a thorough understanding of the pathophysiology of mucus plugging atelectasis and the alterations in pulmonary mechanics. ${ }^{7}$ However, the leading causes of morbidity and mortality in spinal cord injury population are airway mucus plugging and atelectasis. ${ }^{8}$

Progressive resistive exercises are recommended for increasing respiratory muscle strength and endurance in cervical and high thoracic spinal injuries, so that locomotor training is an effective procedure for improving pulmonary function in patients with SCI due to improvement in respiratory muscle function. ${ }^{1}$ However, respiratory muscle training resulted in improved values of vital capacity (VC), maximal inspiratory mouth pressure (PImax) and maximal expiratory mouth pressure (PEmax) in patients with cervical SCI. ${ }^{9}$

This study is designed to investigate the effect of respiratory muscle training on arterial blood gases and pulmonary function in patients with spinal cord injury. 


\section{Materials and methods}

\section{Subjects}

Thirty six patients with complete spinal cord injury at level from C5 to $\mathrm{C} 8$ of both sexes (23 males and 9 females), their age ranged from 23-41 years (30.51 \pm 6.82 year) were selected from ICU of Cairo University Hospital participated in this study. Their height ranged between $149-185 \mathrm{~cm}$. Exclusion criteria included chest infection, cardiac disorders, severe anemia, rib fracture and neurological disorders rather than spinal cord injury. Participants equally enrolled to either training group (group A) or control group (group B).

\section{Equipment}

1. Acid-Base Analyzer: Acid-base analyzer (model 318 ph, Bayer corporation, USA) was a computerized device used to measure partial pressure of arterial oxygen $\left(\mathrm{PaO}_{2}\right)$, partial pressure of arterial carbon dioxide $\left(\mathrm{PaCO}_{2}\right)$ and $\mathrm{PH}$.

2. Intensive care unit monitor: A computerized Trinitron Color Graphic Monitor (Model Sony- PGM-100 p, Sony Corporation, Tokyo, Japan) was a screened device connected through cables to patient. It was used to monitoring vital signs of patient include heart rate (HR), Respiratory rate (RR), Blood pressure (BP) and electrocardiogram (ECG).

3. Spirometer: A portable spirometer (Microspiro Model (HI198), Tokyo, Japan) was used in measuring pulmonary function included forced vital capacity (FVC) and forced expiratory volume in the first second $\left(\mathrm{FEV}_{1}\right)$.

\section{Procedures}

The respiratory muscle-training program for group (A) was started after the clinical stability of patient condition and continued for six weeks of training program. The patient assumed a seating position on wheelchair with head-up tilt about $45^{\circ}$ and inspiratory muscle trainer with a threshold positive expiratory pressure device (Respironics Inc., Cedar Grove, NJ) using a three-way valve system (Airlife 001504, Allegiance Healthcare Corp., McGaw Park, IL) via flanged mouthpiece. The patient performed six work sets, five minutes in duration, with a rest period in between for three minutes. All patients received a 45 minutes training/day, five days/ week for six weeks. The training intensity was initiated with $20 \%$ of each individual maximal inspiratory mouth pressure (PImax) and maximal expiratory mouth pressure (PEmax) and progressively increased as tolerated up to $40 \%$ of PImax and PEmax at the end of the training program. ${ }^{10-12}$

\section{Statistical analysis}

Data concerning each patient were collected in the first evaluation including arterial blood gases $\left(\mathrm{PaO}_{2}, \mathrm{PaCO}_{2}\right.$ and $\left.\mathrm{pH}\right)$, pulmonary function ( $\mathrm{FVC}$ and $\mathrm{FEV} 1$ ), heart rate and respiratory rate. These data were also collected after 6 weeks in the final evaluation. However, paired " $t$ " test was used to determine the significance of difference in mean value between the results observed in the first and the final evaluations of $\left(\mathrm{PaO}_{2}, \mathrm{PaCO}_{2}, \mathrm{PH}, \mathrm{FVC}, \mathrm{FEV} 1, \mathrm{HR}, \mathrm{RR}\right)$ for all patients in both groups, while independent " $\mathrm{t}$ " test used to compare between both groups $(\mathrm{P}<0.05)$.

\section{Results}

The demographic data were presented in Table 1 the mean value of patients' age in group (A) and group (B) were 36.24 \pm 7.37 and $34.95 \pm 6.14$ year respectively. Regarding the gender were 5 females with $(31 \%)$ and 11 males with $(69 \%)$ in group (A), while four females with $(25 \%)$ and 12 males with (75\%) in group (B). Concerning the level of spinal cord injury, there were 14 patients $(88 \%)$ had lower cervical lesion (C6-8), while the other 2 patients (12\%) had middle cervical lesion (C3-5) in group (A), while 13 patients (81\%) had lower cervical lesion (C6-8), while the other 3 patients (19\%) had middle cervical lesion (C3-5) in group (B). However, the mean duration for spinal cord injury in group (A) and group (B) were $5.3 \pm 1.14$ and $4.92 \pm 1.36$ months and ranged from $2-6$ months respectively. Moreover, the smoking history revealed that there were 10 smokers $(63 \%)$ all of them were male, while 6 were nonsmoker (37\%) in group (A), while there were 9 smokers $(56 \%)$ all of them were male, while 7 were nonsmoker (44\%) in group (B).

As observed in Table 2 the mean value of $\mathrm{HR}, \mathrm{RR}, \mathrm{PaCO}_{2}$ and $\mathrm{PH}$ revealed significant reduction, where $\mathrm{FVC}$, FEV1 and $\mathrm{PaO}_{2}$ revealed significant increase in group (A) at the end of the study. However, changes in group (B) were not significant (Table 3). Moreover, there were significant differences between both groups at the end of the study (Table 4) $(\mathrm{P}<0.05)$.

Table I Demographic characteristics of all patients

\begin{tabular}{lllll}
\hline Variables & Mean士SD & \multicolumn{3}{l}{ No. (\%) } \\
\hline Statistics & Group (A) & Group (B) & Group (A) & Group (B) \\
\hline Age (year) & $31.24 \pm 7.37$ & $29.95 \pm 6.14$ & - & - \\
Sex & & & & \\
Males & - & - & $11(69 \%)$ & $12(75 \%)$ \\
Females & & $5(31 \%)$ & $4(25 \%)$ \\
Level of lesions & & & \\
C 3-5 & - & & $14(88 \%)$ & $13(81 \%)$ \\
C 6-8 & & $2(12 \%)$ & $3(19 \%)$ \\
Duration of injury (month) & $5.3 \pm 1.14$ & $4.92 \pm 1.36$ & - & - \\
Smoking history & & & & \\
Smoker & - & - & $10(63 \%)$ & $9(56 \%)$ \\
Non-Smoker & & $6(37 \%)$ & $7(44 \%)$ \\
\hline
\end{tabular}


Table 2 Mean value and significance of $\mathrm{HR}, \mathrm{RR}, \mathrm{FVC}, \mathrm{FEVI}, \mathrm{PaO}_{2}, \mathrm{PaCO}_{2}$ and $\mathrm{PH}$ in group (A) before and at the end of the study

\begin{tabular}{lllll}
\hline \multicolumn{1}{c}{ Statistics } & Mean + SD & & t- value & Significance \\
\cline { 1 - 2 } Variable & Before & After & & \\
\hline $\mathrm{HR}($ beat $/ \mathrm{min})$ & $114.26 \pm 12.23$ & $100.47 \pm 11.65^{*}$ & 10.18 & $\mathrm{P}<0.05$ \\
$\mathrm{RR}($ breath/min) & $18.29 \pm 2.18$ & $15.23 \pm 1.94^{*}$ & 6.57 & $\mathrm{P}<0.05$ \\
$\mathrm{FVC}(\%$ predicated) & $51.15 \pm 8.72$ & $62.17 \pm 9.54^{*}$ & 7.16 & $\mathrm{P}<0.05$ \\
$\mathrm{FEVI}(\%$ predicated $)$ & $78.22 \pm 9.14$ & $90.26 \pm 10.28^{*}$ & 9.25 & $\mathrm{P}<0.05$ \\
$\mathrm{PaO}(\mathrm{mmHg})$ & $80.24 \pm 7.12$ & $89.11 \pm 8.35^{*}$ & 8.26 & $\mathrm{P}<0.05$ \\
$\mathrm{PaCO}_{2}(\mathrm{mmHg})$ & $43.16 \pm 6.19$ & $37.25 \pm 5.84^{*}$ & 6.38 & $\mathrm{P}<0.05$ \\
$\mathrm{PH}$ & $7.46 \pm 0.36$ & $7.38 \pm 0.21^{*}$ & 3.51 & $\mathrm{P}<0.05$ \\
\hline
\end{tabular}

$\mathrm{HR}$, heart rate; RR, respiratory rate; FVC, forced vital capacity; FEV, forced expiratory volume in the first second; $\mathrm{PaO}$, Partial pressure of arterial oxygen; $\mathrm{PaCO}_{2}$, partial pressure of arterial carbon dioxide $(*)$ indicates a significant difference between the two groups, $\mathrm{P}<0.05$.

Table 3 Mean value and significance of $\mathrm{HR}, \mathrm{RR}, \mathrm{FVC}, \mathrm{FEV}_{1}, \mathrm{PaO}_{2}, \mathrm{PaCO}_{2}$ and $\mathrm{PH}$ in group (B) before and at the end of the study.

\begin{tabular}{|c|c|c|c|c|}
\hline \multirow{2}{*}{$\begin{array}{l}\text { Statistics } \\
\text { Variable }\end{array}$} & \multicolumn{2}{|l|}{ Mean + SD } & \multirow[t]{2}{*}{ t- value } & \multirow[t]{2}{*}{ Significance } \\
\hline & Before & After & & \\
\hline HR (beat/min) & $116.48 \pm 13.15$ & $119.11 \pm 13.42$ & $\mathrm{I} .4 \mathrm{I}$ & $P>0.05$ \\
\hline RR (breath/min) & $19.72 \pm 2.54$ & $20.14 \pm 2.36$ & 0.93 & $P>0.05$ \\
\hline FVC(\% predicated) & $49.31 \pm 7.86$ & $47.63 \pm 8.12$ & I.15 & $P>0.05$ \\
\hline FEVI (\% predicated) & $76.54 \pm 8.65$ & $74.82 \pm 8.71$ & 1.38 & $\mathrm{P}>0.05$ \\
\hline $\mathrm{PaO}_{2}(\mathrm{mmHg})$ & $78.92 \pm 6.48$ & $77.61 \pm 6.75$ & 1.26 & $P>0.05$ \\
\hline $\mathrm{PaCO}_{2}(\mathrm{mmHg})$ & $44.53 \pm 5.61$ & $45.67 \pm 5.72$ & 1.13 & $P>0.05$ \\
\hline $\mathrm{pH}$ & $7.47 \pm 0.32$ & $7.48 \pm 0.35$ & 0.54 & $P>0.05$ \\
\hline
\end{tabular}

$\mathrm{HR}$, heart rate; RR, respiratory rate; FVC, Forced vital capacity; FEV , forced expiratory volume in the first second; PaO, Partial pressure of arterial oxygen; $\mathrm{PaCO}_{2}$, partial pressure of arterial carbon dioxide

Table 4 Mean value and significance of $\mathrm{HR}, \mathrm{RR}, \mathrm{FVC}, \mathrm{FEV}, \mathrm{PaO}_{2}, \mathrm{PaCO}_{2}$ and $\mathrm{PH}$ in group $(\mathrm{A})$ and group $(\mathrm{B})$ at the end of the study

\begin{tabular}{|c|c|c|c|c|}
\hline \multirow{2}{*}{$\begin{array}{l}\text { Statistics } \\
\text { Variable }\end{array}$} & \multicolumn{2}{|l|}{ Mean + SD } & \multirow[t]{2}{*}{ t- value } & \multirow[t]{2}{*}{ Significance } \\
\hline & Group (A) & Group (B) & & \\
\hline HR (beat/min) & $100.47 \pm 11.65^{*}$ & $119.11 \pm 13.42$ & 8.23 & $P<0.05$ \\
\hline RR (breath/min) & $15.23 \pm 1.94 *$ & $20.14 \pm 2.36$ & 5.14 & $P<0.05$ \\
\hline FVC(\% predicated) & $62.17 \pm 9.54^{*}$ & $47.63 \pm 8.12$ & 5.86 & $P<0.05$ \\
\hline FEVI (\% predicated) & $90.26 \pm 10.28 *$ & $74.82 \pm 8.7 \mid$ & 7.35 & $P<0.05$ \\
\hline $\mathrm{PaO}_{2}(\mathrm{mmHg})$ & $89.11 \pm 8.35^{*}$ & $77.61 \pm 6.75$ & 6.19 & $P<0.05$ \\
\hline $\mathrm{PaCO}_{2}(\mathrm{mmHg})$ & $37.25 \pm 5.84^{*}$ & $45.67 \pm 5.72$ & 5.24 & $P<0.05$ \\
\hline $\mathrm{pH}$ & $7.38 \pm 0.21 *$ & $7.48 \pm 0.35$ & 3.12 & $P<0.05$ \\
\hline
\end{tabular}

$\mathrm{HR}$, heart rate; RR, respiratory rate; FVC, forced vital capacity; $\mathrm{FEV}_{1}$, forced expiratory volume in the first second; $\mathrm{PaO}{ }_{2}$, Partial pressure of arterial oxygen; $\mathrm{PaCO}_{2}$ : partial pressure of arterial carbon dioxide; $(*)$ indicates a significant difference between the two groups, $\mathrm{P}<0.05$.

\section{Discussion}

Cervical spinal cord injury induce weakness and/or paralysis in respiratory muscle and altered pulmonary function, however respiratory complications are the common cause of death and one of the most common medical complications. Therefore those SCI patients need specific assessment and management of their respiratory condition. ${ }^{5,13}$ The current study aimed to detect the efficacy of resistive inspiratory muscle training program on blood gases pulmonary function in patients with acute cervical spinal cord injury.

Results of this study reveals that there was significant improvement in partial pressure of arterial oxygen $\left(\mathrm{PaO}_{2}\right)$, partial pressure of arterial carbon dioxide $\left(\mathrm{PaCO}_{2}\right)$ and $\mathrm{PH}$ following six weeks of resistive respiratory muscle training program $(\mathrm{p}<0.05)$. Our results coincided with results of Golder et al. ${ }^{15}$ who found that mean value of $\mathrm{PaCO}_{2}$ 
significantly decreased, while the mean value of $\mathrm{PaO}_{2}$ significantly increased in rate underwent hemisecting at $\mathrm{C} 2$ level who received respiratory muscle training. ${ }^{14}$ While, Gregoretti et al. ${ }^{15}$ demonstrated significant reduction of $\mathrm{PaCO}_{2}$ in patients with acute quadriplegic injury after ventilatory training. ${ }^{15}$ However, Wanke et al. ${ }^{16}$ found an increase of $\mathrm{PaO}_{2}$ and decrease in $\mathrm{PaCO}_{2}$ after inspiratory muscle training in patients with Duchenne Muscular Dystrophy. ${ }^{16}$

Concerning pulmonary function, results of this study reveals that there was significant improvement in forced vital capacity (FVC) and forced expiratory volume $\left(\mathrm{FEV}_{1}\right)$ in the first second after six weeks of resistive respiratory muscle training $\operatorname{program}(\mathrm{p}<0.05)$. These results supported by the work of Lin et al. ${ }^{17}$ concluded that abdominal weight and inspiratory resistance load improved ventilatory function parameters in patients with tetraplegia. ${ }^{17}$ However, Derrikson et al. found significant improvement of FVC patient with C 4-8 spinal cord lesion after abdominal weight training. ${ }^{18}$ Moreover, Liaw et al. ${ }^{19}$ demonstrated statistically significant increase in FVC of patients with tetraplegia following abdominal weight and inspiratory resistance load for 6 weeks. ${ }^{19}$ Similarly, Rutchik et al. reported significant improvement in FVC after eight weeks of training in patients with chronic cervical spinal cord injury. ${ }^{20}$ Moreover, Aslan et. Proved that resistive respiratory muscle training for one month significantly improved blood pressure regulation and pulmonary function (FVC and $\mathrm{FEV}_{1}$ ) in patients with $\mathrm{C} 3-\mathrm{T} 2$ chronic spinal cord lesion. ${ }^{7}$ Finally, Berlowitz and Tamplin in their meta-analysis study, which included 11 studies on patients with cervical spinal cord injury, stated that Respiratory muscle training significantly improved vital capacity, maximal inspiratory pressure and maximal expiratory pressure. ${ }^{9}$ The most possible explanations of these results included improve strength and endurance of the respiratory muscle as results of resistive training. ${ }^{12,20}$

\section{Conclusion}

Resistive respiratory muscle training improves blood gases and pulmonary function suggesting this intervention as an efficacious therapy for patients with cervical spinal cord injury.

\section{Acknowledgments}

Author thanks all colleagues who shared in selection of participants and clamp procedures of this study, also author is grateful for the cooperation of the patients participated in this study.

\section{Conflict of interest}

The Authors declare no conflict of interests

\section{References}

1. Tiftik T, Gökkaya N, Malas F, et al. Does locomotor training improve pulmonary function in patients with spinal cord injury?. Spinal Cord. (2015);53:467-470.

2. Terson de Paleville D, Lorenz D. Compensatory muscle activation during forced respiratory tasks in individuals with chronic spinal cord injury. Respir Physiol Neurobiol. 2015;217:54-62.
3. West CR, Campbell IG, Romer LM. Assessment of pulmonary restriction in cervical spinal cord injury: a preliminary report. Arch Phys Med Rehabil. 2012;93(8):1463-1465.

4. Schilero GJ, Spungen AM, Bauman WA, et al. Pulmonary function and spinal cord injury. Respir Physiol Neurobiol. 2009;166(3):129-141.

5. Galeiras VR, Rascado SP, Mourelo FM, et al. Respiratory management in the patient with spinal cord injury. Biomed Res Int. 2013;2013:168-757.

6. Postma K, Haisma JA, Groot S, et al. Changes in pulmonary function during the early years after inpatient rehabilitation in persons with spinal cord injury: a prospective cohort study. Arch Phys Med Rehabil. 2013;94(8):1540-1546.

7. Aslan S, Randall D, Krassioukov A, et al. Resistive respiratory training improves blood pressure regulation in individuals with chronic spinal cord injury. Arch Phys Med Rehabil. 2016;97(6):964-973.

8. Brown R, Dimarco A, Hoit J, et al. Respiratory dysfunction and management in spinal cord injury. Respir Care. 2016;51(8): 853-870.

9. Berlowitz D, Tamplin J. Respiratory muscle training for cervical spinal cord injury. Spinal Cord. 2014;52(3):175-80.

10. Larson JL, Covey MK, Wirtz SE, et al. Cycle ergometer and inspiratory muscle training in chronic obstructive pulmonary disease. Am J RespirCrit Care Med. 1999;160(2):500-507.

11. Griffiths LA, McConnell AK. The influence of inspiratory and expiratory muscle training upon rowing performance. Eur $J$ Appl Physiol. 2007;99(5):457-466.

12. Mueller G, Perret C, Spengler CM. Optimal intensity for respiratory muscle endurance training in patients with spinal cord injury. $J$ Rehabil Med. 2006;38(6):381-386.

13. Kelly A, Garshick E, Erica R, et al. Spirometry testing standards in spinal cord injury. Chest. 2003;123(3):725-730.

14. Golder F, Fuller D, Davenport P, et al. Respiratory motor recovery after unilateral spinal cord injury: eliminating crossed phrenic activity decreases tidal volume and increases contralateral respiratory motor output. The Journal of Neurosciencs. 2003;23(6):2494-2501.

15. Gregoretti C, Olivieri C, Navalesi P. Physilogic comparison between convetional mechanical ventilation and transtracheal openventilation in acute traumatic quadriplegic. Crit Care Med. 2005;33(5):1111-1118.

16. Wanke T, Karl T, Monika M, et al. Inspiratory muscle training in patients with duchenne muscular dystrophy. Chest. 1994;105 (2):475-482.

17. Lin $\mathrm{K}$, Chuang $\mathrm{G}$, $\mathrm{Wu} \mathrm{H}$, et al. Abdominal weight and inspiratory resistance; their immediate effects on inspiratory muscle functions during maximal voluntary breathing in chronic tetraplegic patients. Arch Phys Med Rehabil. 80(7):741-745.

18. Derrickson J, Ciesia N, Simpson N, et al. A comparsion of two Breathing Exercise programs for patients with quadriplegia. Physical Therapy. 1992;72(11):763-769.

19. Liaw M, Lin M, Cheng P, et al. Resistive inspiratory muscle training; it effectiveness in patients with acute complete cervical cord injury. Arch Phys Med Rehabil. 2000;81(6):752-756.

20. Rutchik A, Weissman A, Almenoff $P$, et al. Resistive inspiratory muscle Training in subjects with chronic cervical spinal cord injury. Arch Phys Med Rehabil. 1998;79(3):293-297. 